\title{
Effects of initial disease status on lymph flow following gastrectomy in cases of carcinoma in the remnant stomach
}

\author{
Shinsaku Honda ${ }^{1} \cdot$ Etsuro Bando $^{1} \cdot$ Rie Makuuchi $^{1} \cdot$ Masanori Tokunaga $^{1} \cdot$ \\ Yutaka Tanizawa $^{1}$ - Taiichi Kawamura ${ }^{1}$. Teiichi Sugiura ${ }^{2} \cdot$ Yusuke Kinugasa $^{2}$. \\ Katsuhiko Uesaka ${ }^{2} \cdot$ Masanori Terashima $^{1}$ (i)
}

Received: 16 March 2016/Accepted: 29 August 2016/Published online: 16 September 2016

(c) The International Gastric Cancer Association and The Japanese Gastric Cancer Association 2016

\begin{abstract}
Purpose In cases of carcinoma in the remnant stomach (CRS), the lymphatic flow may be altered by the initial surgery. In this study of CRS after gastrectomy, we investigated how the regions of lymph node metastasis and changes in lymphatic flow depend on initial disease status. Method The study included 76 patients with CRS who underwent gastrectomy between September 2002 and November 2014. We analyzed and compared the clinicopathological factors and survival periods between patients after distal gastrectomy for malignant disease (group M, 33 patients) and patients after distal gastrectomy for benign disease (group B, 43 patients).

Results The depth of tumor invasion was more advanced in group B (T1/T2/T3/T4: group M 18/1/7/7, group B 8/11/ $8 / 16 ; P=0.002)$. However, the degree of lymph node metastasis did not differ significantly between the two groups. The incidence of lymph node metastasis was high at stations $2(19 \%)$, 4sa (17\%), 10 (25\%), 11p (19\%), and $11 \mathrm{~d}(27 \%)$ in group $\mathrm{M}$ and $1(14 \%), 3(23 \%)$, and 4 sb $(15 \%)$, and the mesojejunal lymph node $(21 \%)$ in group B. Lymph node dissection was highly beneficial at station 3, station 7, and the mesojejunum in both groups, but not at stations 10 or $11 \mathrm{~d}$.
\end{abstract}

Electronic supplementary material The online version of this article (doi:10.1007/s10120-016-0640-2) contains supplementary material, which is available to authorized users.

Masanori Terashima

m.terashima@scchr.jp

1 Division of Gastric Surgery, Shizuoka Cancer Center, 1007 Shimonagakubo, Nagaizumi-Cho, Shizuoka 411-8777, Japan

2 Division of Gastroenterological Surgery, Shizuoka Cancer Center, Shizuoka, Japan
Conclusion As compared with group B, group M showed higher incidences of lymph node metastasis in the greater curvature, splenic hilum, and lymph nodes along the splenic artery, suggesting the predominance of lymphatic flows from the greater curvature to the splenic hilum and from the remnant stomach to the splenic artery.

Keywords Carcinoma in the remnant stomach . Lymphatic flow $\cdot$ Splenectomy

\section{Introduction}

The incidence of carcinoma in the remnant stomach (CRS) after distal gastrectomy has been reported to be between 1 and $5 \%$ [1-3]. Although cases of CRS are commonly reported in the literature, the prognosis of CRS has not improved over the past two decades. Instead, the prognosis of CRS (and particularly advanced CRS) remains poor in comparison with the prognosis of primary gastric cancer [4-6]. Moreover, a consensus is yet to be reached regarding therapeutic methods for CRS, and the optimal ranges for resection and lymph node dissection for CRS are unclear $[4,7]$. The major reason for the difficulty involved in treating CRS is mainly the anatomical changes around the stomach and celiac axis caused by the initial surgery.

In cases of CRS, it appears that changes in lymphatic flow can occur as consequences of lymph node dissection, vascular dissection, anastomosis, and gastrointestinal adhesions from the initial surgery [8,9]. For example, metastasis to the mesojejunal lymph nodes has been reported after Billroth II (B-II) reconstruction, and changes to lymphatic flow due to gastrointestinal anastomosis have been observed $[4,10]$. However, it remains unclear how the lymphatic flow changes in CRS. Recently, the number of 
cases of CRS after distal gastrectomy for malignant disease (group M) has been increasing. Unlike in CRS after distal gastrectomy for benign disease (group B), the lymph nodes around the celiac artery are immediately dissected in group $M$ cases. Accordingly, changes in lymphatic flow may follow different patterns in group $B$ and group $M$ cases. Nevertheless, most studies of lymphatic flow have investigated group B patients. Indeed, no previous study has reported the changes in lymphatic flow in patients in group $\mathrm{M}$, or the optimal range for lymph node dissection $[4,8,9]$.

This study aimed to compare the regions of lymph node metastases and lymphatic flow between cases in group B and in group $\mathbf{M}$.

\section{Patients and methods}

\section{Patients}

CRS was defined in accordance with the Japanese Classification of Gastric Carcinoma (English edition, ver. 3) [11], and included all patients with gastric cancers that may have occurred in the remnant stomach after gastric resection, regardless of the disease at the time of the initial surgery, the extent of resection, or the method of reconstruction. Of the gastric cancer patients who underwent operations at our hospital between September 2002 and November 2014, 89 matched this definition. Eleven of those patients were excluded from the present study because they did not undergo total gastrectomy: 7 underwent subtotal resection of the residual stomach, 2 underwent local excision, and 2 underwent bypass surgery. In addition to those 11 patients, 2 patients who received pancreatoduodenectomy as their initial surgery were also excluded. The 76 remaining patients were included and analyzed in this study. The initial surgery was distal gastrectomy in all 76 subjects.

\section{Data collection}

Patient information was extracted from data that had been registered prospectively in an electronic medical records system. The presence of postoperative complications was defined as grade IIIa or higher according to the ClavienDindo classification [12]. The region of the tumor was classified as an anastomotic site or a non-anastomotic site, and the circumference was identified as the region that was predominantly occupied. The clinicopathological factors and survival periods of the patients were compared between the two initial disease states: malignant (group M) and benign (group B). The regions of lymph node metastases and the incidences at those regions were studied in detail. The clinicopathological factors were also categorized according to the Japanese Classification of Gastric
Carcinoma (English edition, ver. 3) [11]. The institutional review board of the Shizuoka Cancer Center approved the collection and analysis of the relevant data.

\section{Statistical analysis}

Statistical analysis was performed using the $\mathrm{R}$ statistical programming language (version 3.1.1; $\mathrm{R}$ Foundation for Statistical Computing, Vienna, Austria). $P$ values of less than 0.05 were considered to indicate statistical significance. To test for significant differences between the two groups, Fisher's exact probability test and the MannWhitney $U$ test were used for nominal scales and continuous variables, respectively. The Kaplan-Meier method was used to estimate overall survival (OS) in each group, and survival rates were compared using the log-rank test. The frequency of lymph node metastasis was calculated with the number of dissected cases as the denominator and the number of positive cases of lymph node metastasis as the numerator. The index of estimated benefit from lymphnode dissection (IEBLD) was calculated for each lymph node station [13]. This index was calculated by multiplying the frequency of metastasis at the lymph node station by the 5-year survival rate of the patients who experienced metastasis at that station. The IEBLD was only calculated for patients who underwent $\mathrm{R} 0$ resection.

\section{Results}

\section{Patient and clinical characteristics}

There were 33 patients $(43.4 \%)$ in group $\mathrm{M}$ and 43 patients $(56.6 \%)$ in group B. The patients' background characteristics are summarized in Table 1 . There was no difference in age or sex between the two groups. The time interval that had elapsed between the previous gastrectomy and the current diagnosis was markedly longer in group B than in group M. Initial B-I and B-II reconstructions were common in group $\mathrm{M}$ and group $\mathrm{B}$, respectively. CRS occurred more often at the anastomotic site in group B, while it occurred more often at the non-anastomotic site in group M. There was no significant difference in circumferential tumor involvement between the two groups. There were more symptomatic cases at the initial consultation in group $\mathrm{B}$, whereas there were more asymptomatic cases at the initial consultation in group $\mathrm{M}$.

\section{Surgical characteristics and pathological findings}

Table 2 shows the surgical findings and pathological results. The operative duration was significantly longer in group $\mathbf{M}$; however, there was no significant difference 
Table 1 Patient characteristics

\begin{tabular}{|c|c|c|c|}
\hline & Group M & Group B & $P$ value \\
\hline Number of patients & 33 & 43 & \\
\hline \multicolumn{4}{|l|}{ Sex } \\
\hline Male & 25 & 39 & \multirow[t]{2}{*}{0.113} \\
\hline Female & 8 & 4 & \\
\hline \multicolumn{4}{|l|}{ Age (years) } \\
\hline Median & 72 & 72 & \multirow[t]{2}{*}{0.124} \\
\hline Range & $50-86$ & $61-86$ & \\
\hline Time interval (years) & 12 & 42 & \multirow[t]{2}{*}{$<0.001$} \\
\hline Range & $1-30$ & $20-63$ & \\
\hline \multicolumn{4}{|l|}{ Reconstruction method } \\
\hline Billroth I & 23 & 9 & \multirow[t]{3}{*}{$<0.001$} \\
\hline Billroth II & 5 & 34 & \\
\hline Roux-en-Y & 5 & 0 & \\
\hline \multicolumn{4}{|l|}{ Region of tumor } \\
\hline Anastomotic & 5 & 31 & \multirow[t]{2}{*}{$<0.001$} \\
\hline Non-anastomotic & 28 & 12 & \\
\hline \multicolumn{4}{|l|}{ Circumference } \\
\hline Less $^{\mathrm{a}}$ & 16 & 15 & \multirow[t]{5}{*}{0.075} \\
\hline $\mathrm{Gre}^{\mathrm{b}}$ & 1 & 9 & \\
\hline $\mathrm{Ant}^{\mathrm{c}}$ & 7 & 4 & \\
\hline Post $^{\mathrm{d}}$ & 5 & 11 & \\
\hline $\operatorname{Circ}^{\mathrm{e}}$ & 4 & 4 & \\
\hline \multicolumn{4}{|l|}{ Symptom } \\
\hline Presence & 9 & 29 & \multirow[t]{2}{*}{0.001} \\
\hline Absence & 24 & 14 & \\
\hline
\end{tabular}

${ }^{a}$ Lesser curvature

b Greater curvature

c Anterior wall

d Posterior wall

e Circumferential involvement

between the amount of blood loss in the two groups. Furthermore, there was no significant difference in the degree of lymph node dissection or the combined resection rate of other organs. The proportion of the patients who underwent splenectomies was $39 \%$ in group $\mathrm{M}$ and $56 \%$ in group B. Both groups had approximately the same rate of R0 excision (85\% in group $\mathrm{M}$ and $84 \%$ in group B). The number of dissected lymph nodes was markedly higher in group B.

Group $M$ tended to exhibit a higher rate of postoperative complications, but the difference between the groups was not statistically significant. Anastomotic leaks and pancreatic fistulas tended to occur more often in group $\mathbf{M}$. Complications were observed in 15 of the 31 patients (48 \%) in whom splenectomy was performed.

In histopathological estimates, the incidence of deeper invasion was higher in group B; however, there was no significant difference in $\mathrm{N}$ or $\mathrm{p}$ stage between the two groups. None of the patients with pT1 disease had lymph node metastasis in either group.

\section{Incidence of lymph node metastasis according to the initial disease state}

Table 3 shows the incidence of lymph node metastases in each group. Higher incidences of lymph node metastasis were observed at lymph node stations 2, 4sa, 7, 9, 10, 11p, and $11 \mathrm{~d}$ in group $\mathrm{M}$, whereas higher incidences of metastasis were observed at stations $1,3,4 \mathrm{sb}, 10$, and $11 \mathrm{~d}$ and the mesojejunal lymph node in group B.

Figure 1 shows the incidences of metastasis at lymph node stations where this incidence was $\geq 5 \%$ and the number of patients who underwent dissection was at least 10. In group B, high incidences of lymph node metastasis were observed in the lesser curvature of the remnant stomach, along the splenic artery, in the splenic hilum, and at the mesojejunal lymph node. Three separate lymph flows were observed in group B: from the lesser curvature to the celiac artery, from the greater curvature to the splenic hilum, and from the remnant stomach to the anastomotic site. In group $\mathrm{M}$, high incidences of lymph node metastasis were observed in the greater curvature of the remnant stomach, the splenic hilum, and lymph nodes along the splenic artery. In group $M$, lymphatic flows from the greater curvature of the remnant stomach to the splenic hilum and from the remnant stomach to the splenic artery had become predominant.

\section{Survival outcomes and IEBLDs}

The 5-year OS rate was $48.6 \%$ in group $\mathrm{M}$ and $53.5 \%$ in group B. There was no significant difference in OS between the two groups $(P=0.947)$.

Table 4 shows the IEBLDs for various lymph node stations in the 64 patients who underwent $\mathrm{R} 0$ resection. The median follow-up period for these patients was 1250 days (range, 36-3, 977 days). Dissection was deemed beneficial at stations 3 and 7 and the mesojejunal lymph nodes based on their high IEBLDs, and also at stations 1, 2, 4sb, and $11 \mathrm{p}$, but surprisingly not at stations 10 and $11 \mathrm{~d}$, despite the high incidences of metastasis to these stations. This tendency was observed in both group $\mathrm{M}$ and group $\mathrm{B}$.

\section{Discussion}

In this investigation of clinicopathological factors based on initial disease status, we observed that the operative duration was markedly longer, that early cancers were more common, and that the number of harvested lymph nodes 
Table 2 Surgical findings and pathological results for the patients

\begin{tabular}{|c|c|c|c|}
\hline & Group M $(n=33)$ & Group B $(n=43)$ & $P$ value \\
\hline \multicolumn{4}{|l|}{ Operation time (min) } \\
\hline Median & 273 & 235 & \multirow[t]{2}{*}{0.033} \\
\hline Range & $129-505$ & $123-520$ & \\
\hline \multicolumn{4}{|l|}{ Bleeding $(\mathrm{mL})$} \\
\hline Median & 547 & 404 & \multirow[t]{2}{*}{0.586} \\
\hline Range & $69-6622$ & $78-1564$ & \\
\hline \multicolumn{4}{|l|}{$\mathrm{LN}_{\text {dissection }}{ }^{\mathrm{a}}$} \\
\hline $\mathrm{D} 1, \mathrm{D} 1+$ & 21 & 24 & \multirow[t]{2}{*}{0.638} \\
\hline D2 & 12 & 19 & \\
\hline Combined resection $^{\mathrm{b}}$ & 13 & 18 & \multirow[t]{5}{*}{1} \\
\hline Spleen & 13 & 18 & \\
\hline Distal pancreas & 3 & 3 & \\
\hline Liver & 5 & 1 & \\
\hline Colon & 1 & 4 & \\
\hline \multicolumn{3}{|l|}{$\mathrm{R}$ status } & \multirow[t]{3}{*}{1} \\
\hline R0 & 28 & 36 & \\
\hline $\mathrm{R} 1 / 2$ & 5 & 7 & \\
\hline \multicolumn{4}{|l|}{ Number of dissected LNs } \\
\hline Median & 12 & 27 & \multirow[t]{2}{*}{$<0.001$} \\
\hline Range & $3-35$ & $2-66$ & \\
\hline \multicolumn{4}{|l|}{ Clinical stage } \\
\hline \multicolumn{4}{|l|}{ Early } \\
\hline Median & 10 & 27 & \multirow[t]{2}{*}{0.008} \\
\hline Range & $3-35$ & $6-48$ & \\
\hline \multicolumn{4}{|l|}{ Advanced } \\
\hline Median & 19 & 25.5 & \multirow[t]{2}{*}{0.051} \\
\hline Range & $3-34$ & $2-66$ & \\
\hline Morbidities ${ }^{\mathrm{c}}$ & 13 & 8 & \multirow[t]{8}{*}{0.069} \\
\hline Leakage & 5 & 1 & \\
\hline Pancreatic fistula & 5 & 2 & \\
\hline Intra-abdominal abscess & 1 & 0 & \\
\hline Intra-abdominal bleeding & 1 & 2 & \\
\hline Bile fistula & 1 & 0 & \\
\hline Ileus & 0 & 2 & \\
\hline Pneumonia & 0 & 1 & \\
\hline \multicolumn{4}{|l|}{ Histological type } \\
\hline Differentiated & 12 & 17 & \multirow[t]{2}{*}{0.816} \\
\hline Undifferentiated & 21 & 26 & \\
\hline \multicolumn{4}{|l|}{ Tumor depth } \\
\hline $\mathrm{T} 1(\mathrm{M} / \mathrm{SM})$ & 18 & 8 & \multirow[t]{4}{*}{0.002} \\
\hline $\mathrm{T} 2$ (MP) & 1 & 11 & \\
\hline T3 (SS) & 7 & 8 & \\
\hline T4 (SE/SI) & 7 & 16 & \\
\hline \multicolumn{4}{|l|}{ Nodal status } \\
\hline No & 22 & 27 & \multirow[t]{4}{*}{0.939} \\
\hline N1 & 5 & 6 & \\
\hline $\mathrm{N} 2$ & 2 & 5 & \\
\hline N3 & 4 & 5 & \\
\hline
\end{tabular}


Table 2 continued

\begin{tabular}{llll}
\hline & Group M $(n=33)$ & Group B $(n=43)$ & $P$ value \\
\hline Pathological stage & & & \\
I & 19 & 16 & 0.136 \\
II & 5 & 14 & \\
III & 3 & 8 & \\
IV & 6 & 5 & \\
\hline
\end{tabular}

Modified based on the extent of LN dissection for primary tumor according to the Japanese Gastric Cancer Treatment Guidelines and the Japanese Classification of Gastric Carcinoma

${ }^{a}$ Lymph nodes dissected for D1: nos. 1, 2, 3, 4sa, 4sb, 7, (mesojejunum: J1); for D1+: those for D1+nos. 8a, 9, 11p; for D2: those for D1+nos. 8a, 9, 10, 11p, 11d, (mesojejunum: J2). The definitions refer to the extent of lymph node dissection for primary gastric cancer [14]

b Including duplicate

${ }^{c}$ Clavien-Dindo classification grade IIIa or higher

Table 3 Incidences of lymph node metastasis at various lympth node stations in each group

\begin{tabular}{|c|c|c|c|c|c|c|}
\hline \multirow{2}{*}{$\begin{array}{l}\text { Lymph node } \\
\text { station }\end{array}$} & \multicolumn{3}{|l|}{ Group M } & \multicolumn{3}{|l|}{ Group B } \\
\hline & $\begin{array}{l}\text { Number of } \\
\text { dissected } \\
\text { patients }\end{array}$ & $\begin{array}{l}\text { Number of } \\
\text { metastatic } \\
\text { patients }\end{array}$ & $\begin{array}{l}\text { Incidence of lymph } \\
\text { node metastasis }(\%)\end{array}$ & $\begin{array}{l}\text { Number of } \\
\text { dissected } \\
\text { patients }\end{array}$ & $\begin{array}{l}\text { Number of } \\
\text { metastatic } \\
\text { patients }\end{array}$ & $\begin{array}{l}\text { Incidence of lymph } \\
\text { node metastasis }(\%)\end{array}$ \\
\hline 1 & 22 & 2 & 9.1 & 42 & 6 & 14.3 \\
\hline 2 & 32 & 6 & 18.8 & 40 & 3 & 7.5 \\
\hline 3 & 13 & 1 & 7.7 & 40 & 9 & 22.5 \\
\hline $4 \mathrm{sa}$ & 30 & 5 & 16.7 & 43 & 2 & 4.7 \\
\hline $4 \mathrm{sb}$ & 16 & 1 & 6.3 & 40 & 6 & 15.0 \\
\hline 7 & 3 & 1 & 33.3 & 41 & 3 & 7.3 \\
\hline $8 a$ & 8 & 0 & 0 & 29 & 1 & 3.4 \\
\hline 9 & 7 & 2 & 28.6 & 34 & 2 & 5.9 \\
\hline 10 & 12 & 3 & 25.0 & 19 & 3 & 15.8 \\
\hline $11 \mathrm{p}$ & 21 & 4 & 19.0 & 30 & 3 & 10 \\
\hline $11 \mathrm{~d}$ & 15 & 4 & 26.7 & 22 & 3 & 13.6 \\
\hline Mesojejunum & 4 & 0 & 0 & 24 & 5 & 20.8 \\
\hline
\end{tabular}

tended to be lower in group $\mathrm{M}$ than in group B. Patients in group $\mathrm{M}$ also tended to have a higher incidence of complications, which might be attributable to the different levels of surgical difficulty involved in the cases included in groups B and M. It has previously been reported that surgeries for CRS are difficult $[4,15,16]$. In group $M$ patients, in addition to the lymph node dissection around the celiac artery during the initial surgery, the omental bursa and greater omentum were removed in some cases [17]. Therefore, high degrees of adhesion were observed around the remnant stomach. The high incidence of pancreatic fistulas in group $\mathrm{M}$ may be partly or wholly explained by strong adhesions between the pancreas and the remnant stomach at the time of initial surgery, and by the presence of scarred tissue caused by the lymph node dissection at the superior border of the pancreas. In addition, the high rates of anastomotic leaks in group $\mathrm{M}$ could be due to secondary pancreatic juice leaks. Ohashi et al. observed high rates of pancreatic fistulas and anastomotic leaks, and suggested that they could be linked to the combined resection of other organs [5]. Of the 13 patients in their study who suffered complications, nine had undergone combined resection, and those patients exhibited similar complications to those stated above.

The lymph node count was significantly lower in group $\mathrm{M}$ than in group $\mathrm{B}$. This was expected because lymph node dissection had already been performed during the initial surgery in group M. In the current study, both groups showed the same incidence of lymph node metastasis. In previous reports, however, the incidence of lymph node metastasis was higher in group B [6, 18-20]. This could be explained by the fact that the number of remaining lymph 


\section{Group M}

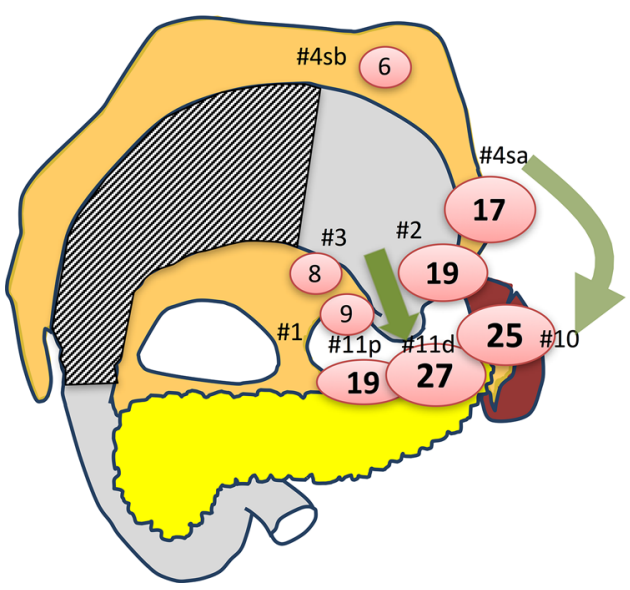

Fig. 1 Rates of metastasis at lymph node stations where the incidence of metastasis was $>5 \%$ and the number of cases that required dissection was $\geq 10$. The incidence of metastasis was relatively high at stations $2,4 \mathrm{sa}, 10$, and 11 in group $\mathrm{M}$, whereas it was relatively high at station 3 and the mesojejunal lymph nodes in group B. The flows of lymph from the greater curvature to the splenic

Table 4 Indices of estimated benefit from lymph node dissection for R0

\begin{tabular}{llll}
\hline $\begin{array}{l}\text { Lymph node } \\
\text { station }\end{array}$ & $\begin{array}{l}\text { Incidence of } \\
\text { lymph node } \\
\text { metastasis }(\%)\end{array}$ & $\begin{array}{l}\text { 5-Year } \\
\text { survival } \\
\text { rate }(\%)\end{array}$ & $\begin{array}{l}\text { Index of estimated } \\
\text { benefit from lymph } \\
\text { node dissection }\end{array}$ \\
\hline 1 & 5.5 & 66.7 & 3.6 \\
2 & 4.9 & 33.3 & 1.6 \\
3 & 14.6 & 66.7 & 9.7 \\
$4 \mathrm{sa}$ & 3.2 & 0 & 0 \\
$4 \mathrm{sb}$ & 2.1 & 100 & 2.1 \\
7 & 5.3 & 100 & 5.3 \\
$8 \mathrm{a}$ & 0 & 0 & 0 \\
9 & 5.6 & 50 & 0 \\
10 & 4.3 & 0 & 0 \\
$11 \mathrm{p}$ & 9.1 & 33.3 & 3 \\
$11 \mathrm{~d}$ & 10.3 & 0 & 0 \\
Mesojejunum & 12.5 & 50 & 6.3 \\
\hline
\end{tabular}

nodes was higher in group B. In group $\mathrm{M}$, the incidence of lymph node metastasis was $0 \%(0 / 19)$ in patients with T1/ T2 disease and $78.6 \%(11 / 14)$ in patients with T3/T4 disease. On the other hand, in group B, the incidence was $12.6 \%(3 / 16)$ in patients with T1/T2 disease and $54.2 \%$ (13/24) in patients with T3/T4 disease. The incidence of lymph node metastasis tended to increase sharply once the tumor had invaded deeper than T3 in group M. This observation may be explained by the higher biological malignancy of group $\mathrm{M}$ advanced cancers with deeper invasion $[4,5,21]$.

\section{Group B}

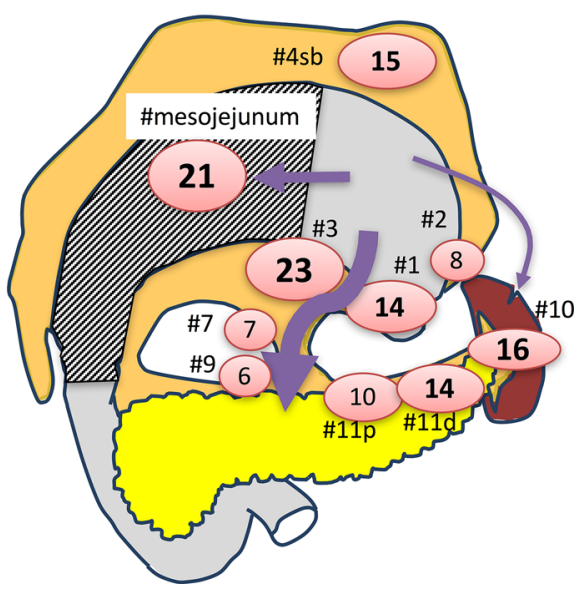

hilum and from the remnant stomach to the splenic artery were predominant in group $\mathrm{M}$. The flows of lymph from the lesser curvature to the celiac artery and from the remnant stomach to the anastomotic site were predominant for group B. Modified from [17] with permission

There appeared to be three flows of lymph in group B: from the lesser curvature to the celiac artery, from the greater curvature to the splenic hilum, and from the remnant stomach to the anastomotic site. Excluding the flow to the anastomotic site, the lymphatic flows were similar to those in the gastric cancers that normally occurred in the upper third of the stomach. The lymphatic flows from the greater curvature to the splenic hilum and from the remnant stomach to the splenic artery appeared to be predominant in group M. Previous studies have reported that the frequencies of lymph node metastasis in the splenic hilum and along the splenic artery are higher in CRSs than in primary cancers at the upper third of the stomach [4, 22, 23]. These reports have primarily been on benign initial disease. In our study, we also observed higher rates of metastasis to stations 10 and 11 for CRS than for primary cancer of the upper third of the stomach. Indeed, even patients in group $\mathrm{B}$ were associated with higher rates of metastasis to stations 10 and 11 (15.8 and $11.5 \%$, respectively) than primary cancer of the upper third of the stomach (14.2 and $9.9 \%$, respectively). The rates of metastasis to stations 10 and 11 tended to be even higher in group M (25 and $22 \%$, respectively).

It is well known that the site of lymph node metastasis is largely related to the site of the tumor. The results of the JCOG0110 trial, which examined the importance of splenectomy in advanced primary gastric cancer, showed that splenectomy could be omitted if the lesion was not a greater curvature lesion [24]. We examined the influence of circumferential location of the tumor (Table S1 in the Electronic supplementary material, ESM). The incidence 
of station 10 lymph node metastasis was $40 \%$ for greater curvature tumors in group B, but $0 \%$ for lesser curvature tumors in group $\mathrm{M}$. There is no question that the circumferential location of the tumor strongly influences the site of lymph node metastasis. However, even though tumors located at the posterior wall and greater curvature tended to be less common in group $\mathrm{M}$ (posterior wall: 1; greater curvature: 5 ; total: $6 / 33$ ) than in group $\mathrm{B}$ (posterior wall: 11; greater curvature: 9 ; total: 20/43), the incidences of metastasis in the greater curvature, in the splenic hilum, and along the splenic artery were higher in group $M$ than in group B. These results suggest that lymphatic flow is strongly influenced by initial disease.

In the present study, the 5-year survival rate was $36 \%$ for patients with stage II disease and $33 \%$ for patients with stage III disease. More than 20 years ago, Sasako et al. reported 5 -year survival rates of $40 \%$ for patients with stage II disease and $39 \%$ for patients with stage III disease, rates that are not especially different from our own [4]. Di Leo et al. recently reported 5-year survival rates of $37.8 \%$ for T2 disease and $33.1 \%$ for T3-4 disease [25]. Together, these findings indicate that, despite progress in intensive therapies, the therapeutic outcomes for advanced CRS have hardly changed at all over the past 20 years. In a comparison of a more recent period with a prior period, Takahashi et al. found a better survival rate in the more recent period [20]. These findings do not show an improvement in therapeutic outcomes, but they do indicate that better diagnostic abilities have increased the number of CRSs that are discovered early.

The importance of splenectomy in the treatment of CRS remains unclear. Ohashi et al. observed that the incidence of lymph node metastasis at the splenic hilum and along the splenic artery was $26 \%$ in group M. Considering the potential effects of dissection, total gastrectomy involving splenectomy has become a recommended procedure [5]. Our current study revealed that the lymphatic flow toward the splenic hilum was predominant in group M. To perform a complete lymph node dissection of the splenic hilum and along the splenic artery, splenectomy must be performed. However, the present study's findings make it difficult to claim that splenectomy is beneficial for advanced CRS (not only in group B, but also in group M). Twenty years ago, Kodera et al. reported an extremely low 5-year survival rate for CRS with group 2 lymph-node metastasis [7]. Ohashi et al. reported a 5-year survival rate of $23 \%$ for advanced CRS with lymph-node metastasis [5]. In our study, the 5-year survival rate of patients with lymph-node metastasis was $18 \%$. The prognosis for CRS with lymphnode metastasis is poor, and dissection provides insufficient benefits. The therapeutic results for advanced CRS are nowhere near satisfactory. In addition to dissection, novel attempts need to be verified, including neoadjuvant chemotherapy and strong chemotherapy.
In group $\mathrm{B}$, the incidence of mesojejunal lymph node metastasis was high, followed by the incidence of metastasis to station 3 . The mesojejunal lymph node has been included in the regional lymph nodes in the Japanese Classification of Gastric Carcinoma (English edition ver.3) [11]. However, solid evidence on the effects of mesojejunal lymph node dissection is lucking. Di Leo et al. reported that the 5-year survival rate for CRS with mesojejunal lymph node metastasis after B-II reconstruction was $17.1 \%$ [25]. Thorban et al. reported that the median survival period for patients with mesojejunal lymph node metastasis was 13.2 months; therefore, their survival outcome was reported to be poor [26]. The current study showed that mesojejunal lymph node dissection was beneficial, based on the high IEBLDs. Therefore, the mesojejunal lymph nodes should be dissected in patients who undergo B-II reconstruction.

The limitations of this research include the retrospective, single-institution design of the study. Given the small sample size, no statistically significant difference in the frequencies of lymph node metastases could be detected. However, a clear distinction was observed between the areas where lymph node metastases occurred; thus, the findings of this report appear promising. The current study of CRS is the first to present the differences in the pattern of lymph node metastasis between group B and group M. Prospective research on CRS is difficult because of the wide range of variations in the frequencies of disease onset and background factors. We anticipate that the analysis of a large-scale, nationwide registry system could help to provide beneficial findings in the future.

In conclusion, the results of this study suggest that the lymphatic flows from the greater curvature to the splenic hilum and from the remnant stomach to the splenic artery were predominant in group M. Since lymph node dissection provides insufficient benefit in cases with metastasis to the splenic hilum or along the splenic artery, aggressive intensive care is probably necessary in such cases.

Acknowledgments This research was supported by the Practical Research for Innovative Cancer Control (No. 15ck0106043h0002) program of the Japan Agency for Medical Research and Development, AMED.

\section{Compliance with ethical standards}

Conflict of interest The authors declare that they have no conflicts of interest.

Ethical standards All procedures followed were in accordance with the ethical standards of the responsible committee on human experimentation (institutional and national) and with the Helsinki Declaration of 1964 and later versions. Informed consent or a substitute for it was obtained from all patients before they were included in the study. 


\section{References}

1. Ikeda Y, Saku M, Kishihara F, Maehara Y. Effective follow-up for recurrence or a second primary cancer in patients with early gastric cancer. Br J Surg. 2005;92:235-9.

2. Nozaki I, Nasu J, Kubo Y, Tanada M, Nishimura R, Kurita A. Risk factors for metachronous gastric cancer in the remnant stomach after early cancer surgery. World J Surg. 2010;34:1548-54.

3. Onodera H, Tokunaga A, Yoshiyuki T, Kiyama T, Kato S, Matsukura N, et al. Surgical outcome of 483 patients with early gastric cancer: prognosis, postoperative morbidity and mortality, and gastric remnant cancer. Hepatogastroenterology. 2004;51:82-5.

4. Sasako M, Maruyama K, Kinoshita T, Okabayashi K. Surgical treatment of carcinoma of the gastric stump. Br J Surg. 1991;78:822-4.

5. Ohashi M, Morita S, Fukagawa T, Kushima R, Katai H. Surgical treatment of non-early gastric remnant carcinoma developing after distal gastrectomy for gastric cancer. J Surg Oncol. 2015;111:208-12.

6. Tokunaga M, Sano T, Ohyama S, Hiki N, Fukunaga T, Yamada $\mathrm{K}$, et al. Clinicopathological characteristics and survival difference between gastric stump carcinoma and primary upper third gastric cancer. J Gastrointest Surg. 2013;17:313-8.

7. Kodera Y, Yamamura Y, Torii A, Uesaka K, Hirai T, Yasui K, et al. Gastric stump carcinoma after partial gastrectomy for benign gastric lesion: what is feasible as standard surgical treatment? J Surg Oncol. 1996;63:119-24.

8. Ikeguchi M, Kondou A, Shibata S, Yamashiro H, Tsujitani S, Maeta M, et al. Clinicopathologic differences between carcinoma in the gastric remnant stump after distal partial gastrectomy for benign gastroduodenal lesions and primary carcinoma in the upper third of the stomach. Cancer. 1994;73:15-21.

9. Han SL, Hua YW, Wang CH, Ji SQ, Zhuang J. Metastatic pattern of lymph node and surgery for gastric stump cancer. J Surg Oncol. 2003;82:241-6.

10. Tanigawa N, Nomura E, Niki M, Shinohara H, Nishiguchi K, Okuzawa $\mathrm{M}$, et al. Clinical study to identify specific characteristics of cancer newly developed in the remnant stomach. Gastric Cancer. 2002;5:23-8.

11. Japanese Gastric Cancer Association. Japanese Classification of Gastric Carcinoma: 3rd English edition. Gastric Cancer. 2011;14:101-12.

12. Dindo D, Demartines N, Clavien PA. Classification of surgical complications: a new proposal with evaluation in a cohort of 6336 patients and results of a survey. Ann Surg. 2004;240:205-13.
13. Sasako M, McCulloch P, Kinoshita T, Maruyama K. New method to evaluate the therapeutic value of lymph node dissection for gastric cancer. Br J Surg. 1995;82:346-51.

14. Japanese Gastric Cancer Association. Japanese Classification of Gastric Carcinoma-2nd English Edition. Gastric Cancer. 1998;1:10-24.

15. Safatle-Ribeiro AV, Ribeiro Junior U, Reynolds JC, Gama-Rodrigues JJ, Iriya K, Kim R, et al. Morphologic, histologic, and molecular similarities between adenocarcinomas arising in the gastric stump and the intact stomach. Cancer. 1996;78:2288-99.

16. Pointner R, Wetscher GJ, Gadenstatter M, Bodner E, Hinder RA. Gastric remnant cancer has a better prognosis than primary gastric cancer. Arch Surg. 1994;129:615-9.

17. Japanese Gastric Cancer Association. Japanese Gastric Cancer Treatment Guidelines 2010 (ver. 3). Gastric Cancer. 2011;14:113-23.

18. Kodera Y, Yamamura Y, Torii A, Uesaka K, Hirai T, Yasui K, et al. Gastric remnant carcinoma after partial gastrectomy for benign and malignant gastric lesions. J Am Coll Surg. 1996;182:1-6.

19. Lee SB, Kim JH, Kim DH, Jeon TY, Kim DH, Kim GH, et al. Clinicopathological characteristics and prognosis of remnant gastric cancer. J Gastric Cancer. 2010;10:219-25.

20. Takahashi M, Takeuchi H, Tsuwano S, Nakamura R, Takahashi $\mathrm{T}$, Wada N, et al. Surgical resection of remnant gastric cancer following distal gastrectomy: a retrospective clinicopathological study. Ann Surg Oncol. 2016;23:511-21.

21. Ohashi M, Katai H, Fukagawa T, Gotoda T, Sano T, Sasako M. Cancer of the gastric stump following distal gastrectomy for cancer. Br J Surg. 2007;94:92-5.

22. Imada T, Rino Y, Hatori S, Shiozawa M, Takahashi M, Amano T, et al. Clinicopathologic differences between early gastric remnant cancer and early primary gastric cancer in the upper third of the stomach. Hepatogastroenterology. 2000;47:1186-8.

23. Komatsu S, Ichikawa D, Okamoto K, Ikoma D, Tsujiura M, Nishimura Y, et al. Progression of remnant gastric cancer is associated with duration of follow-up following distal gastrectomy. World J Gastroenterol. 2012;18:2832-6.

24. Sano T, Sasako M, Mizusawa J, Yamamoto S, Katai H, Yoshikawa T, et al. Randomized controlled trial to evaluate splenectomy in total gastrectomy for proximal gastric carcinoma. Ann Surg. 2016. doi:10.1097/SLA.0000000000001814.

25. Di Leo A, Pedrazzani C, Bencivenga M, Coniglio A, Rosa F, Morgani P, et al. Gastric stump cancer after distal gastrectomy for benign disease: clinicopathological features and surgical outcomes. Ann Surg Oncol. 2014;21:2594-600.

26. Thorban S, Bottcher K, Etter M, Roder JD, Busch R, Siewert JR. Prognostic factors in gastric stump carcinoma. Ann Surg Oncol. 2000;231:188-94. 